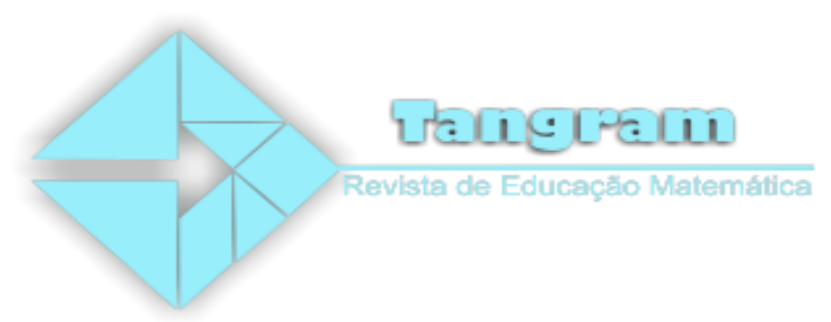

\title{
Apresentação: Pesquisas sobre o ensino e aprendizagem de Matemática
}

Esta edição conta com 7 investigações organizadas em artigos científicos e relatos de experiência. Temos 5 artigos científicos , 4 de diferentes instituições brasileiras (Paraná, Rio de Janeiro, Pará, Rio Grande do Norte e São Paulo ) e um artigo estrangeiro( México) Divulgamos ainda dois relatos de experiência oriundos de diferentes instituições brasileiras (Ceará e Pernambuco)

De modo geral, identificamos que os artigos trazem contribuições para o ensino e aprendizagem de Matemática.

Assim, o artigo de Maria Cristina Otto, Fátima Aparecida Queiroz Dionizio e Celia Finck Brandt, intitulado “O papel das crenças e emoções no desenvolvimento da afetividade em relação à matemática nos anos iniciais do ensino fundamental" iniciam a edição mencionando sobre os sentimentos e como estes podem influenciar o ensino de Matemática nos anos iniciais do Ensino Fundamental.

O segundo artigo intitulado "Aprimorando o desempenho de futuros profissionais em matemática financeira" escrito por Geneci Alves de Sousa e Lilian Nasser apresentam um estudo do curso de Ciências Contábeis sobre a formação financeira, no qual identificouse que com a aplicação de um pré-teste e pós-teste as dificuldades dos estudantes.

A terceira pesquisa de Márcio José Silva, Fábio José da Costa Alves e Claudianny Amorim Noronha, intitulada "O ensino de probabilidade com questões sociais" traz uma proposta de ensinar probabilidade utilizando os aspectos sociais , pois os autores acreditam que estas relações são mais atraentes para que ocorra a aprendizagem.

$\mathrm{O}$ artigo "O juro real no contexto da educação financeira crítica”, escrito por Celso Ribeiro Campos e Cileda Queiroz e Silva Coutinho também estabelecem relações com a prática social, e nos traz reflexões sobre o conceito de letramento financeiro e sua utilização do juro real no cotidiano dos brasileiros.

Tangram - Revista de Educação Matemática, Dourados - MS - v.2 n. 2, pp. 01-02 (2019) 
Assim, o quinto artigo científico intitulado "Enseñanza de estocásticos a niños con discapacidad. Un acercamiento" epistemológico , de autoria de J. Marcos López-Mojica e Catalina Navarro Sandoval. Os autores apresentam um estudo sobre o ensino de estatística para alunos de 8-10 anos com dificuldade de aprendizagem desenvolvido no México, promovendo diferentes reflexões sobre as possibilidades de inclusão para ensinar Matemática.

$\mathrm{O}$ sexto artigo trata-se de um relato de experiência, intitulado "Trigonometria e suas aplicações no Geogebra: aulas experimentais com alunos do ensino médio" de autora de Italândia Ferreira de Azevedo e Francisco Régis Vieira Alves sobre o uso de tecnologias como software para o ensino de alguns conteúdos específicos no Ensino Médio, trazendo reflexões sobre as diferentes estratégias que podem ser utilizadas.

O último relato de experiência intitulado A história da matemática como instrumento metodológico no ensino do Teorema de Tales, escrito por Anderson Rodrigo Oliveira da Silva, Fernando Emílio Leite de Almeida, Eduardo Gomes Lopes e Francinette Mendes Lopes. Os autores nos trazem um relato de experiência desenvolvido no primeiro ano do ensino médio, sobre o uso da história da Matemática voltado para o ensino do Teorema de Tales, no qual evidenciou-se uma boa compreensão dos estudantes sobre o conteúdo.

Assim, desejamos uma boa leitura à todos

Editores

Edvonete Souza de Alencar

Tiago Dziekaniak Figueiredo

Aldrin Cleyde da Cunha

Adriana Fátima de Souza Miola

Tangram - Revista de Educação Matemática, Dourados - MS - v.2 n. 2, pp. 01-02 (2019) 